\title{
Un jesuita en los límites de la religión: Joannes Alexius Schabel y la misión de Curazao (1698-1715)
}

\author{
Andrés Castro Roldán \\ Universidad de París III, Francia \\ castro.roldan@neuf.fr
}

\begin{abstract}
Resumen
Este artículo expone la problemática misional del jesuita checo Joannes Alexius Schabel durante el periodo de la guerra de sucesión (1703-1713). Se analiza en él, particularmente, el tema del poder pastoral desde el ángulo de la observancia religiosa y de los conflictos entre misioneros en la isla de Curazao, territorio por entonces bajo control de judíos y calvinistas, pero próximo al mundo católico del continente (Venezuela).
\end{abstract}

Palabras clave: Joannes Alexius Schabel, misionero, siglo XVIII, Curazao, Casanare.

\begin{abstract}
This article analyses the missional work and difficulties of the Jesuit Joannes Alexius Schabel during the period of the War of Spanish Succession (1702-1713). It will focus particularly on the problem of pastoral power through the angle of religious observance as well as conflictual relations between missionnaries in the island of Curaçao, by the time under control of Jews and Calvinists but boundary with the catholic world of the spanish continent (Venezuela).
\end{abstract}

Key words: Joannes Alexius Schabel, missionnary, 18th century, Curaçao, Casanare.

\section{Introducción}

En 1741 fue publicada en Córdoba (España) una obra póstuma de carácter parenético del jesuita Juan Rivero (1681-1736), misionero español de los llanos del Meta en el Nuevo Reino de Granada. El libro, titulado Teatro del desengaño, estaba destinado a los jóvenes nobles de Santa Fe para ayudarles a "escoger estado"; es decir, optar entre ser clérigos, religiosos o padres de familia. Escrita en una retórica típicamente barroca, inspirada en los Autos Sacramentales de 
Calderón, la obra pone en escena varios personajes emblemáticos que introducen una problemática edificante y ejemplar. Así, un joven caballero llamado el escarmiento, perdido "en lo enmarañado de la selva", se encuentra de repente en una caverna con el desengaño, la experiencia, su madre y el escardillo, su jardinero. Este último es una especie de mensajero del desengaño que trae a cuento los defectos y los vicios que separan del camino de la virtud a los jóvenes religiosos. Habiendo viajado por el mundo entero, y particularmente por las colonias holandesas de Curazao, Surinam y Berbiz, el escardillo cuenta cómo un joven y virtuoso religioso se encuentra en las calles de Ámsterdam con un viejo apóstata de su orden "muy estimado antes y de harto puesto en su religión, y a quien el padre pasajero había conocido":

Atónito el buen religioso de ver a su conocido en tal traje y naturaleza, no pudo menos que decirle entre suspenso y admirado: pues Padre, ¿es posible Vuestra Paternidad en este traje? ¿Y la Conciencia? A esto respondió muy sereno: Dejemos eso Vuestra Paternidad por lo que toca a la conciencia, le diré lo que pasa: Cuando tomé este estado (era de casado y con hijos) tuve mis remordimientos y escrúpulos, pero desde que Dios me dio estos niños, se me quitaron. (Rivero 161)

El uso de tal ejemplo no es fruto de la imaginación del padre Rivero, quien se sirve de la propia experiencia en la provincia jesuita de Nueva Granada, de la que fue un testigo conspicuo. Rivero se refiere aquí, sin lugar a dudas, a un antiguo misionero de Casanare: el padre checo Michael Joannes Alexius Schabel, cuyo caso concierne al presente estudio.

El padre Schabel nació en 1662 en el pueblo de Chomutov, provincia de Bohemia, en el seno de una familia de origen alemán. A los 19 años entró al colegio jesuita de Praga, donde hizo su noviciado y sus estudios de teología y donde enseñó luego por 4 años el latín y las humanidades. En 1695 zarpaba para América, donde era afecto a las misiones de los Llanos. En 1698 se encontraba en la isla de Curazao rumbo a Holanda. En Europa Schabel permaneció 5 años viajando de una provincia a otra antes de volver a América. Estuvo algún tiempo en los Países Bajos, entre Amberes, Ámsterdam y Rótterdam, antes de viajar a Praga en 1700. De allí debió pasar a Roma y regresar de nuevo a Ámsterdam en 1701. Viajó luego a España, pasando por Zaragoza y Madrid, donde permaneció algunos meses en 1702. En Cádiz se embarcó hacia Lisboa, y haciendo escala luego en Londres, hacia mayo de 1703, debió volver a la ciudad de Rótterdam y zarpar de allí nuevamente hacia Venezuela en 1704. Su estadía en el continente fue breve, pues fue acusado de espionaje y apostasía y debió volver a la isla de Curazao, donde se desempeñaría como misionero por 9 años. En 1713 era llamado de regreso a Holanda, acusado de amancebamiento y expulsado de la Compañía al año 
siguiente. De esta fecha en adelante su biografía enmudece, al punto de que no sabemos dónde vivió luego ni en qué fecha murió.

Hacia 1715, cuando el padre Rivero, entonces de 34 años, pasaba su tercera probación, la Provincia de Nueva Granada recibía la noticia de la expulsión del misionero checo, lo que debió de impresionar sobremanera al joven jesuita español: ¿Cómo era posible que un padre profeso de 54 años se encontrara casado y con hijos en un país protestante?

El caso del padre Schabel (1661-?), como se percibe ya por la intensa actividad biográfica, es excepcional dentro de la prosopografía de los misioneros jesuitas en América. No es tanto porque se trate de un caso de apostasía, pues hay numerosos casos como este en la historia jesuita de la antigua compañía (1558-1767), sino por encontrarse al mismo tiempo en el límite de la profesión religiosa, entre el celo misionero y el compromiso o activismo del mundo laico, en la frontera geográfica entre el continente español y el espacio periférico de las nuevas potencias coloniales (francesa, holandesa e inglesa) y, en fin, en una coyuntura histórica marcada por cambios importantes en la política colonial europea (1698-1715). Los escritos de Schabel, dirigidos desde Curazao al General Tamburini en Roma, son, así mismo, interesantes, pues parecen alejarse del típico formato edificante. Todo esto hace que el caso Schabel abra nuevos interrogantes sobre la vocación religiosa, la naturaleza del poder pastoral jesuita, su alcance en la esfera política y la realidad del trabajo misionero, infinitamente más complejo y contradictorio de como nos es presentado por la historiografía jesuita.

\section{¿Apostasía o celo indiscreto?}

Desde el punto de vista de la observancia religiosa, las acciones y pensamientos del jesuita, manifiestos tanto en los documentos coloniales como en sus escritos, revelan una actitud paradójica: investido de su vocación, manifiesta desde que pide su traslado a América (indipetae) y confirma su cuarto voto en Casanare, y hasta su regreso como misionero a Curazao, su celo misionero parece mantenerse a medida que se multiplican sus viajes, mientras que poco a poco va dejando de lado los votos simples de obediencia, pobreza y castidad.

\section{Desobediencia}

Una de las pruebas de una cierta tendencia a la insubordinación la encontramos en los Catalogi Secundi ${ }^{1}$ de la curia romana, donde las autoridades jesuitas conservaban una "contabilidad moral y disciplinaria" sobre cada uno de los miem-

Estas informaciones fueron cuidadosamente anotadas por la historiadora Christine Schunck a partir de los Catalogi Secondi del archivo (ARSI, BOH f. 21, 22, 24,26; cfr. Schunck 154). 
bros de la compañía (que para entonces ya sobrepasaban los 15.000), lo cual les permitía el manejo racional de la información necesaria para la nominaciones y promociones. Las calificaciones de Schabel pasan de buenas a mediocres justamente en el año de 1693, cuando el Jesuita pedía, con insistencia, al general Tirso Gonzáles su envío a las misiones de Nueva Granada (ARSI, FG 756 f. 39). Schabel tenía entonces 32 años y se encontraba en el colegio de Praga, a punto de pasar su tercera probación.

En septiembre de 1695, después de una larga estadía en Sevilla, Schabel y otros 45 jesuitas atravesaban el Atlántico rumbo a Cartagena de Indias (Rey Fajardo 21). El grupo no llegaría a Santa Fe sino hasta el mes de mayo de 1696. En febrero del año siguiente el padre checo se encontraba ya en Casanare, donde pronunciaba el voto final que lo haría jesuita profeso. Los superiores lo enviaron luego a una misión en la región de Barinas, al norte de Casanare. Allí Schabel obtuvo el apoyo de un doctrinero llamado Diego Bragado, propietario de una importante hacienda.

Sin embargo, su actividad misionera no duraría más que un año. En el mes de agosto de 1698 aparece misteriosamente en la isla de Curazao. Schabel salía de allí para Europa, sin ninguna autorización de sus superiores, ni permiso alguno de las autoridades españolas. ¿Le ocurrió acaso algo grave que lo haya hecho salir de improviso? Los historiadores proponen varias hipótesis.

La holandesa Christine Schunck sugiere un choque grave con los superiores, que habría tenido por causa la acogida poco calurosa por parte de los jesuitas criollos y españoles de la misión. Esta posibilidad no se puede descartar. Existen varios precedentes en la historia misionera del Casanare, que ponen de manifiesto la poca solidaridad de los jesuitas de habla hispana hacia los franceses ${ }^{2}$, belgas, austriacos y alemanes.

El historiador jesuita Manuel Pacheco propone otra explicación, que es, a mi modo de ver, complementaria. Durante los últimos años del siglo XVII y principios del siglo XVIII los superiores de la provincia parecen haber usado un rigor extremo, al cual los padres de Europa no estaban acostumbrados, lo que explicaría, según Pacheco, que entre 1704 y 1716 se hubieran presentado varias fugas, como las de los padres Francisco Ricci, Javier Yopolo y Juan Obino. El caso del

2 Un rechazo de este tipo se produjo con el padre francés Denis Mesland, quien, sospechoso de ser un espía francés, fue llamado desde Guayana a comparecer en Santa Fe de Bogotá, ante la Real Audiencia, en 1665. 
padre Obino es similar al de Schabel. Obino encontró refugio en Curazao antes de ser expulsado de la Compañía ${ }^{3}$.

Otra hipótesis, desarrollada por la historiadora Analola Borges, es la del espionaje. Ello explicaría el súbito viaje de Schabel a Holanda, donde habría actuado como agente o informante en pro de intereses políticos o económicos relacionados con la Guerra de Sucesión. La hipótesis tampoco se puede descartar, aunque la evidencia histórica solo da cuenta del rol activo de Schabel en varias negociaciones de tipo comercial, realizadas en Europa. Si ello fue en verdad el motivo principal de su viaje lo ignoramos. Lo que sí consta es que la voluntad del jesuita no había sido la de abandonar la Compañía de Jesús, ni mucho menos su cargo de misionero. Su intención era volver a las misiones del Nuevo Reino, como lo testimonia una carta escrita desde Rótterdam a uno de sus amigos de Nueva Granada (AGI, Carta del 17/01/1702 de Schabel a Bragado, SD 794; cfr. Schunck 96), y lo corroboran los hechos posteriores. Igualmente, es significativo que Schabel haya viajado en compañía de un indio de su misión.

La razón oficial que daba a su llegada al colegio jesuita de Amberes era el haber venido en busca de ayuda para la misión del Orinoco, que se encontraba en aprietos (Schunck 95). En 1699 el General Tirso Gonzáles, enterado del desacato, escribía al Provincial de Santa Fe:

Viene sin patente ninguna de Vuestra Reverencia ni de otro superior, sin que sepamos de cierto hasta ahora otro fin de su venida que de llevar sujetos para aquellas misiones, en donde según su declaración habían dado muerte los caribes a los padres Alonso de Neira y José de Silva. Quiera Dios que esta resolución de su celo indiscreto (por no calificarle de otra suerte hasta oírle) no sirva sólo de hacer nuevos gastos a esa provincia [...] pero atendiendo a que su resolución ha nacido de celo, aunque imprudente, me ha pareció no hacer ninguna (severa demostración) porque puesto en Europa ha necesitado más de consuelo que de aflicción. (APT 132 f. 136; cfr. Pacheco 126).

De acuerdo con las órdenes dadas por Gonzáles, el jesuita checo debía regresar inmediatamente a Santa Fe acompañado de otro padre (socio) y ser severamente castigado a su llegada (AGI SF 250 f. 54; ARSI FB 8-1 f. 134v; ARSI EG 52 f. 149-151). En Roma, los registros disciplinarios para el año de 1702 rubricaban en la columna de Prudentia la palabra nulla, prueba de que la insubordinación había sido tomada en cuenta por la curia romana (ARSI, BOH 26; cfr. Schunck 154).

3 En 1709 Obino fue enviado a Curazao para hacer una visita al padre Schabel. Dos años después regresaba nuevamente a Curazao, esta vez pidiendo refugio a Schabel, después de haber sido Expulsado de la Compañía (Pacheco 403). 
Las circunstancias políticas fueron, sin embargo, desfavorables al misionero. A la muerte de Carlos II de España, en 1700, las tensiones políticas que darían luego inicio a la Guerra de Sucesión eran tales que hicieron imposible el regreso de Schabel a territorio hispanoamericano. En 1701, a pesar de tener el apoyo y la autorización de Roma para volver al Nuevo Reino desde Holanda, el permiso para viajar de Ámsterdam a Caracas le fue negado por el embajador español ${ }^{4}$. Siendo de nacionalidad checa y, por ende, súbdito del Imperio Austriaco, Schabel debió viajar a España para formular una nueva autorización. Pero en Cádiz los funcionarios del Consejo de Indias, influenciados por el partido borbónico, le prohibieron de nuevo el viaje, por considerarlo de nacionalidad enemiga. $\mathrm{Su}$ aventura hispanoamericana debía terminar con esta negativa. Una carta del mes de mayo de 1704, firmada por el padre Tamburini, futuro General, le ordenaba su reintegro definitivo al colegio de Praga (Schunck 98).

Pero ya desde 1703, ante las negativas del gobierno español, Schabel había acariciado nuevos planes. Regresar a la vida tranquila de su Bohemia natal no hacía parte de sus proyectos; sobre todo, después de haber atravesado por dos veces el Atlántico y haber visitado las ciudades de Madrid, Zaragoza, Sevilla, Cádiz, Ámsterdam, Rótterdam, Amberes, Londres, Lisboa, Cartagena, Santa Fe y Curazao. Su experiencia en territorio holandés había despertado, tal vez, su celo contrarreformista, inspirado por aquellos jesuitas talentosos en convertir herejes, o acaso fuera, simplemente, el aprecio por la forma de vida de los holandeses la causa de su empeño por regresar como misionero a Curazao. Desde la llegada de los holandeses, en 1634, la vocación eminentemente mercantil de la isla impuso una política de tolerancia religiosa que permitió la migración de comerciantes de distintas nacionalidades y confesiones. Para finales del siglo XVII Curazao contaba con 10.000 habitantes y constituía un punto estratégico para el comercio de esclavos y el tráfico de contrabando europeo hacia el continente (Oostindie 352). Durante su corta estadía en la isla en 1698, Schabel se había dado cuenta de la falta de sacerdotes católicos. En razón de la diversidad de nacionalidades y de lenguas, la comunidad católica se encontraba dispersa y no existían parroquias. Así pues, viéndose frente a la negativa de España, el jesuita proponía a las autoridades de Amberes fundar una misión en esta colonia. El proyecto contaba con el apoyo de Joe Van der Meulen ${ }^{5}$, rico armador católico de Rótterdam que había acogido al jesuita desde la llegada de este a Holanda. El expediente Schabel debió

4 Esta prohibición es comentada por Tamburini en una carta del 11 de febrero de 1702 al Provincial de Flandes. Según Tamburini, el embajador Don Francisco Bernardo de Quirós había prohibido el paso a Schabel y a otro jesuita belga (APF, 8-1 f. 198; Schunck 97).

5 Se trataba de uno de los armadores más ricos de los Países Bajos, como lo prueban sus relaciones con la corte española, en la cual su sobrino, Antonio Meijers, se desempeñaba como tesorero (Schunck 98). 
de crear largas discusiones y carteos entre los Jesuitas flamencos y las autoridades de Roma. En el mes de abril de 1704 Tamburini aprobaba el proyecto, pero ordenaba a Schabel esperar las negociaciones diplomáticas respectivas entre los representantes de la West Indies Company (judíos y calvinistas que controlaban por entonces la isla de Curazao) y los miembros del partido católico holandés (ARSI, FB 8-1 f. 228; cfr. Schunck 98).

En 1704, y por segunda vez, el jesuita desobedecía la orden de Tamburini y viajaba de regreso a Curazao. De nuevo la alta jerarquía jesuita perdonaba su comportamiento, y lo aprobaba a posteriori. Schabel permaneció en la isla como misionero hasta 1713. Los documentos más precisos sobre sus actividades misioneras, conservados en el archivo romano de la Compañía (ARSI), corresponden al periodo que va de 1705 a 1708, tiempo durante el cual el jesuita escribió una larga relación de misión (notitia) y un diario (diurnum) (ARSI, NRQ "Notitia" 16-I f. 1-122; "Diurnum" 16-I: appendix 229). El primer escrito, la relación de 1705 , cuenta algunas de sus más graves dificultades en su primer año de misión, en particular el relato y la justificación de un corto viaje hecho a Caracas y a Barinas entre 1704 y 1705, de donde fue casi expulsado por traidor. En efecto, Schabel, que había pasado a Caracas a dar parte de su misión al obispo y a procurarse nuevo material litúrgico, fue acusado de ser un espía al servicio del archiduque de Austria. Así mismo, los jesuitas del colegio de Mérida lo inculpaban de apostasía y sus antiguos amigos venezolanos le volteaban la espalda. Una denuncia llegó rápidamente al cabildo eclesiástico de Caracas y Schabel tuvo que huir (ARSI, NRQ 16-1 f. 68). El jesuita escribiría en su diario:

Les indiqué (a mis indios) que la cuestión era que por obediencia a mis superiores tenía que volver a la Isla de Curazao. No hay lengua que pueda decir, ni palabras que puedan expresar qué dolor nos ha causado a mí, a ellos y a todos esa despedida, esa separación violenta. Pero, ¿qué hacer? Obedecer por amor de Dios, y por Dios es necesario obedecer, aunque sea hasta la muerte y muerte de cruz. (ARSI, NRQ 16-I; cfr. Arellano,1970:17)

De vuelta a Curazao, la situación era difícil: la Guerra de Sucesión había exacerbado el rechazo por parte de las autoridades y élites de Nueva Granada de toda comunicación con los holandeses, y contribuyó a aislar a Schabel de la jerarquía jesuita de Nueva Granada y de la ayuda de sus antiguos amigos. Con todo, si nos atenemos a sus escritos y a los documentos de la curia romana, el misionero parece asumir su rol de jesuita celoso frente a los calvinistas y judíos de la isla. Su situación parece equivaler a la de los misioneros de Oriente: Schabel debía actuar como un pionero, encontrar por sí mismo la respuesta a las resistencias encontradas y tomar sus propias decisiones. De hecho, su obediencia no existía sino hacia el padre general Tamburini, única fuente de legitimidad de su trabajo. 
Aparentemente, Tamburini le había dado su apoyo y confianza hasta el año de 1715 , en el que fue expulsado de la orden. Es igualmente a Tamburini a quien Schabel escribe sus relaciones misioneras.

Con todo, Tamburini vigilaba de cerca sus actividades. En 1707 el misionero recibía la visita del dominicano fray Diego Lobatón, quien le traía patentes de Roma y autorizaciones del arzobispo de Santo Domingo. Lobatón había logrado restituir la confianza del jesuita escribiendo al Colegio de Santa Fe un testimonio favorable de su celo misionero:

Ya he visto yo en el refitorio del colegio de Santa Fe retratos de misioneros vestidos como seglares pero no había conocido ninguno anteriormente. Quedé estupefacto al ver en carne y hueso en esta isla este misionero, que, actuando como un verdadero varón apostólico vive aquí entre herejes y judíos. ${ }^{6}$ (ARSI, NRQ 16-1:6)

Tal fue, así mismo, el asombro, según cuenta Schabel, del capuchino Víctor de Dôle, sacerdote recién llegado a la isla para atender las necesidades espirituales de la comunidad francesa de Curazao:

Como era yo miembro de la Compañía de Jesús, no podía él dudar de lo que era evidente, en particular de acuerdo a las cartas del padre general y de otros padres. Yo habría creído que sabía que los misioneros holandeses no dicen misa en su hábito religioso cuando están en misión o en su capilla y que no les está permitido utilizarlo en todos lados. Al punto [llegaba su ignorancia] que se había imaginado que no tenía yo hábito alguno. (ARSI, NRQ 16-1 f. 59)

El asombro de Lobatón y de Dôle pone de relieve lo ambiguo de la identidad misionera de Schabel. Este, como en el caso de los misioneros de la China, y como lo prescribían las autoridades calvinistas a todos los clérigos que querían ejercer el sacerdocio en Curazao, debía vestirse como laico y no manifestar en público ningún signo de proselitismo religioso. Esta exigencia debió de ser, desde nuestro punto de vista, un factor desestabilizador para nuestro jesuita.

Se puede decir que su comportamiento en general revela una identidad compleja y ambigua que navega entre un militantismo misionero y un individualismo libre de autoridad, pues su insubordinación no parece haber puesto en tela de

Texto original: "Missionarios Apostolicos Societatis Jesu, saeculariter vestitos pictos vidi in vestro refectorio Collegii Sancta Fidani, nunc vero in hac Insula non pictum sed vivum et verum ejusmodi virum apostolicum inter haereticos et judaeos video et obstupesco" (traducción libre del autor). 
juicio su celo misionero, como lo demuestra la actitud de Tamburini. ¿Acaso no era, pues, esta ambigüedad tolerada necesaria para el buen funcionamiento de las misiones?

\section{¿Comercio apóstata? ¿Actividad de espionaje?}

El diurnum, fragmento de un diario tenido por nuestro misionero entre el 21 de octubre de 1707 y el 2 de febrero de 1708, es uno de los raros documentos misioneros de la época en que aparecen los pensamientos personales de un jesuita registrados cotidianamente. En efecto, pocos son los casos en que este tipo de escritos fueron conservados por la curia romana, que prefería destruir todos los papeles personales que comprometieran la reputación de la orden. De hecho la vida de cada jesuita debía ser escrita de acuerdo con criterios edificantes, y las huellas personales debían desparecer si no eran conformes con estos criterios. Así, la memoria del individuo, contraria al régimen "desparentalizado" de la corporación jesuita, debía ser atenuada o pulida. Las representaciones de los nexos sociales y familiares debían llevarse a su mínima expresión para privilegiar la construcción de una identidad colectiva, de un cuerpo social.

Examinando de cerca el diario, lleno de comentarios personales, lo que sorprende a primera vista es su desorden. Ningún ritmo cotidiano parece deducirse de sus páginas. Los comentarios sobre la comunidad judía, sobre alguno que otro personaje importante o sobre la evolución de sus conflictos con la comunidad católica francesa son desiguales y, a veces, desconcertantes en la pluma de un jesuita. De acuerdo con el diario, Schabel pasaba sus días bautizando esclavos negros, actividad normal en una isla cuyo principal recurso era el comercio negrero. Escribe Schabel: "Mi brazo no se cansa fácilmente cuando bautizo, como el brazo de Moisés se cansaba cuando predicaba" (ARSI, NRQ 16-1 f. 10). Los bautismos, más numerosos los domingos después de la misa, parecen ser la única actividad pastoral consignada con regularidad en el diario. Poco o nada nos dice sobre su vida espiritual o su trabajo cotidiano de predicación, doctrina y confesión, cosa frecuente en las relaciones y escritos jesuitas de la época. Solo son transcritos los acontecimientos excepcionales (como las misas dichas con ocasión de la llegada de algún barco español o la celebración de las fiestas religiosas).

Schabel parece más interesado en los navíos: los piratas, los barcos de guerra y los de comercio. "Nuestro puerto, escribe, se parece al arca de Noé. Al igual que en aquella se encontraban animales de todas las especies, de igual manera, a nues-

Texto original: "Nec facile fatigabitur baptizando, uti Moysis brachia fessa erant orando" (traducción libre del autor). 
tro puerto llegan navíos de toda especie, tanto amigos como enemigos" (ARSI, NRQ 16-1 f. 30). El jesuita registra día a día todos los movimientos del puerto: tipos de barcos que llegan, nacionalidad, proveniencia, actividad, duración de la escala. Los barcos piratas holandeses y franceses parecen interesarle tanto como los navíos y balandras mercantes, sobre los que anota en detalle su calado y tipo de mercancía. Por ejemplo, el 29 de octubre de 1707 apunta la llegada de dos balandras holandesas, pertenecientes a dos comerciantes de la isla, que vuelven de contrabando del Río de El Hacha, en Nueva Granada. El producto de las ventas sumaba unos 70.000 patacones, de los cuales 30.000 debían reinvertirse en la compra de nuevas mercancías (adfert ad merces coëmendas) (ARSI, NRQ 16-1 f. 30).

¿Podemos acaso interpretar la minucia con la cual el jesuita anota estas informaciones como el signo de una actividad de espionaje o de "inteligencia"? El 21 de noviembre de 1707, cuando un barco holandés es asaltado por españoles cerca de la costa venezolana, Schabel parece inquieto cuando se entera de que en el botín, recuperado luego por los habitantes de Curazao, no había ninguna carta de Ámsterdam para él. El misionero se lamenta: "No sé si mis amigos, a los cuales envío cartas en todas las naves que salen de Curazao, estarán muertos o acaso me habrán olvidado. A menos que piensen que ya estoy muerto"; y agrega, con cierto humor: "Ya os lo haré saber cuando esté muerto" (Certiores vos faciam,quando mortuus ero) (ARSI, NRQ 16-1 f. 18). ¿Qué contenía toda esta correspondencia que enviaba a Holanda o a Caracas? ¿Qué le respondían sus amigos? ¿Se trataba acaso de negocios o asuntos de comercio, tal como nos permiten suponer las evidencias que tenemos de sus actividades europeas? En una carta enviada desde Holanda en 1702 a Diego de Bragado, en Caracas, Schabel comunicaba el progreso de las negociaciones que llevaba a cabo para obtener un acuerdo comercial entre Van der Mulen, el cual era entonces capellán en Rótterdam, y dos criollos venezolanos: fray Andrés Venegas y Marcos de Tacoada. Los criollos debían viajar pronto a Holanda en uno de los barcos de la flota de Van der Mulen: la Virgen de Door. Su capitán, Cornelis Leinzen, había sido encargado de traer la carta de Schabel y hacerla llegar a Venezuela (AGI, SD f. 794; cfr. Schunck 96). El acuerdo preveía la exportación de cacao y de tabaco hacia Holanda, para entonces prohibido por el régimen de monopolio español, lo que, de hecho, no tardaría en caer al final de la Guerra de Sucesión, con la paz de Ultrecht (1712-1714). Esta carta sirvió mas tarde a los enemigos de Schabel para acusarlo de espionaje ante el Consejo de Indias. Otra de las negociaciones llevadas a cabo por Schabel durante su estadía en Europa era la exportación de cristal de Bohemia, negocio mediante

Texto original: "Ita nostrer portus similis est Arca Noes. Uti in illa omnis generis animalia, ita in nostro portu omnes generis navis amicorum et inimicorum" (traducción libre del autor). 
el cual el jesuita buscaba financiar la misión de Curazao. La mercancía de cristal tallado debía ser enviada a Rótterdam y a Curazao, para de allí ser distribuida en el continente hispanoamericano. El Jesuita presentaba este proyecto a su superior de Praga en el invierno de 1703 y lo enviaba, igualmente, al padre Tamburini en Roma. Al momento de partir de nuevo a Curazao en 1704, Schabel había recibido tres docenas de copas de cristal, ofrecidas por el duque de Krumlov, a quien el jesuita había conocido en un anterior viaje a Praga en 1701. El misionero había escrito incluso un catalogus vitrorum donde recomendaba a los fabricantes del taller de Vimperk que las copas, destinadas al mercado hispanoamericano, debían ser talladas con motivos típicos: personajes populares con inscripciones en español, motivos de fauna y flora americana, o de minerales como las esmeraldas o el oro, e incluso de las vírgenes de Zaragoza, Guadalupe y Chiquinquirá, o de los escudos de armas de las provincias americanas. Schabel también había hecho un mapa que mostraba la ruta por seguir en Europa para hacer llegar la frágil carga a Rótterdam por Hamburgo o por Venecia (Polisensky 104; Schunck 96).

Como vemos, durante sus viajes por Europa Schabel había hecho amistad con personajes influyentes de la aristocracia mercante. Como ya vimos, durante su estadía en la misión (1697-1698) se amistó con Diego de Bragado, propietario de una de las más grandes haciendas de Barquisimeto y en contacto con los productores de cacao y de tabaco en Venezuela. En Holanda fue el capellán de Joe Van der Mullen. En Praga estaba en contacto con Sebastián von Liebenhausen, administrador del duque de Krumlov, poseedor, a su vez, del monopolio del cristal de Bohemia. En Madrid fue recibido por el sobrino de Van der Mulen, Antonio Maijers, por entonces nada menos que tesorero del rey de España.

En Curazao el jesuita estaba en relación con un personaje influyente que aparece en su relación como el "judío-ateo", pero a quien hemos identificado como el influyente Felipe Henríquez, acusado por el Consejo de Indias de conspiración contra el rey de España, como aliado del archiduque de Austria, y más tarde condenado en Cartagena de Indias por la Inquisición. Estando aún en Curazao, Henríquez había hecho donaciones a favor de la causa de Schabel y lo había presentado a los miembros más eminentes de la comunidad portuguesa de la isla. El jesuita era igualmente amigo de don Gaspar de Andrade, responsable del tráfico de esclavos negros de Guinea y Angola para el continente hispanoamericano. Cada sábado consagraba una misa en honor de la Madre de Dios, de la cual Andrade era particularmente devoto (ARSI, NRQ 16-1 f. 53). Andrade, así mismo, le había donado generosas sumas para la misión, y al momento de partir para Cartagena le dejaba su lujosa habitación frente al puerto de Willemstad, como escribe el jesuita en su diario el 2 de enero de 1708: 
Hoy, varios navíos mercantes han zarpado del puerto. En uno de ellos, viajaba un rico comerciante español al que he sucedido en su habitación. Este comerciante, hombre rico y honesto, regresa a la Nueva Granada y me ha prometido que dará buen testimonio a los jesuitas de Cartagena que conoce y que son sus amigos, del estado de mi santa misión, difícil al principio, pero hermosa y gloriosa para la mayor gloria de Dios y para la salvación de las almas. ${ }^{9}$ (ARSI, NRQ 16-1 f. 28)

Es difícil saber si Schabel se aprovechó personalmente de estas amistades. Todo parece indicar que su rol se limitó al de ser un intermediario, como era a menudo el caso de los jesuitas que tomaban parte en los conflictos privados haciendo uso de su moralidad para resolverlos a cambio de la caridad de los prosélitos. Cuando Schabel viajó a Europa desde Curazao, fue gracias a la generosidad de Diego de Bragado, quien se ocupó de los gastos del viaje. En Madrid algunos comerciantes parecen haberle prestado algún dinero (Schunck 95, 105). En Curazao, como ya vimos, recibió donaciones generosas de parte de Henríquez y de otros miembros de la comunidad judía, por el celo apostólico que manifestaba en bautizar a los esclavos. No hay que olvidar que desde la segunda mitad del siglo XVII los judíos y protestante holandeses tenían el monopolio de esclavos en América (asiento) bajo la condición de que los esclavos debían ser al menos bautizados. En 1708 Schabel vivía cómodamente en la antigua sede de la sociedad Coiman \& Co., domiciliada en Ámsterdam y en Cádiz, y que, como hemos visto, le fue cedida por Henríquez. Situada frente a la sinagoga, la casona era enorme y tenía una capilla privada (Schunck 103). Al parecer, la capilla estaba bien decorada, tenía un clavicordio, e incluso se había mandado a hacer un nuevo tabernáculo. El jesuita pagaba 288 patacones de arriendo. "En mi país [escribe con decepción], me hubiera podido comprar por esa suma, una buena y espaciosa casa" (ARSI, NRQ 16-1 ff. 27, 31).

Es probable que el general Tamburini temiera un mayor acercamiento entre Schabel y los judíos de Curazao, pues en 1708, preocupado por su aislamiento, le prometía ayuda económica, ayuda que no se haría efectiva sino hasta 1710 (ARSI, FB 8-1 f. 274v; 8-II f. 297; cfr. Schunck 105). En 1713 el jesuita parece involucrado en negocios privados, pues Tamburini le escribe nuevamente para ordenarle acabar su "comercio apóstata" (Schunck 106). ¿De qué asunto se trataba, entonces? ¿Era acaso el negocio de cristal de Bohemia que Schabel había

Texto original: "Abierunt a portu nostro complures naves ad commerciam. In una ex ipis unus mercator hispanus, cui in habitatione interina succesi. Hic ad Novum Regnum Granatensis redit, vir probus et dives. Promisit et proposuit, quod patribus nostris sibi notis et amicis sanctae missionis meae statum in principijs suis difficilem, sed majori Dei gloriae, atque animarum saluti pulchrum et gloriosum, ut testis oculatus fuse enarrabit" (traducción libre del autor). 
organizado desde Europa? Esto no parece ser el caso, puesto que el proyecto de importación de cristal contaba con el aval de Roma. Quizás se haya tratado de su colaboración con el medio cripto-judío de Curazao, el cual, como vimos, Tamburini no aprobaba. Las condenas de Tamburini en 1713 y la expulsión de la orden el año siguiente parecen confirmarnos en la idea de que Schabel se habría aprovechado de su posición y de sus relaciones para enriquecerse, pues un año después de su expulsión el jesuita regresaba a Curazao, donde compró una casona por 1.600 pesos (Schunck 106).

\section{Atentado contra la castidad}

E1 27 de septiembre de 1707 Schabel cuenta en su diario sobre una visita que él y otro religioso habían hecho en Zaragoza a una mujer aparentemente poseída. El jesuita parece encontrarse aquí en la estricta ortodoxia de lo que serían las relaciones de un religioso con las mujeres:

Saliendo de mi casa el padre dominicano que es mi huésped, me contó que había bautizado un negrito llamado Francisco y que había exorcizado el demonio de un poseído. Yo no conozco ningún negro que haya sido exorcizado. La cuestión es verdaderamente sorprendente y rara pues he recorriendo el mundo entero sin haberme encontrado jamás con un tal caso. Cuando me encontraba en Zaragoza, capital de Aragón, conocí a una mujer que decían poseída pero yo no la encontré en un tal estado. Fue un cierto Ignacio, padre de nuestra Compañía, quien me llevó a su casa sin advertirme de su estado. En mi presencia, la mujer no manifestó ningún indicio de posesión y nos acogió por el contrario afablemente. En efecto, nos ofreció chocolate y pasteles e hizo tocar el clavicordio a su hija para agradarnos. El padre que me acompañaba me dijo cuando dejamos el lugar: "Estoy sorprendido de ver que aquella mujer, poseída durante tantos años, no haya manifestado el menor signo demoníaco en presencia de vuestra reverencia". [...] ¿Qué podía responderle yo entonces? ¿Qué puedo decir ahora al respecto? ¿Será que el diablo me teme? No lo creo, soy más bien yo quien le teme. ${ }^{10}$ (ARSI, NRQ 16-1 f. 8-9)

$10 \quad$ Texto original: "Solum Caesar Augustae metropoli Aragoniae mulierem vidi energumenam cujusdam patris nostrae matrem nec talem esse scivi. Ad eam visitandam me duxit quidam pater noster Ignatius, nec mihi dixit esse energumena, nisi cum ea jam discesseramus. In mea praesentia ne minimum quidem indicium dedit energumenae, sed omni possibili humanitate me excepit. Nam potu choculate et varijs dulcearijs, nec non musica filiae in clavicordia, uti vocamus, ludentis me recreavit. Socius pater meus mihi in reditu dicebat: Stupeo supramodum, quod in muliere ista tot annis energumenae ne minimum quidem signum daemonium monstraverit in praesentia Reverentiae Vestrae sed admiserit, ut mulier haec energumena in solitam et omni possiblem urbanitatem Reverentiae Vestrae exhiberet, Quid ad hoc dicerem vel dicam? an diabolus me timet? ego ipsum multo magis timeo" (traducción libre del autor). 
En Curazao, sin embargo, la situación era diferente. Schabel no podía llevar el hábito en su trato con los legos, lo que pudo haber creado situaciones ambiguas; sobre todo, en una isla con tanta diversidad humana, en la cual, además, el jesuita se encontraba sin la presión social ni la vigilancia de su corporación religiosa. Con todo, Schabel parece aún investido de su rol de religioso. En 1705 escribe a Tamburini a propósito de un religioso apóstata que se había refugiado en la isla:

A menudo sacerdotes de este tipo se refugian de las colonias españolas en territorio holandés y se vuelven apóstatas. Hace pocos años, entre otros ejemplos del mismo genero, un individuo del que prefiero callar el nombre, llegó aquí y para el escándalo y el dolor de los católicos se convirtió al judaísmo, y después de haberse circuncidado, se casó con una mujer judía. (ARSI, N.R.et Q. 16-1:54).

Cuando en 1707 los primeros rumores de espionaje del jesuita checo llegaron a Roma con el procurador de Madrid, Tamburini, quien ya conocía el asunto, continúa respaldando a su misionero. Sin embargo, decide enviarle visitadores para supervisar su modo de vida y sus actividades apostólicas. En 1709 dos jesuitas vienen a verlo desde Santo Domingo. Otros dos pasaran de nuevo en 1711, a causa de nuevas acusaciones que habían llegado a la Real Audiencia de Santa Fe. Nuevamente en 1713 otro visitador era enviado de Amberes, con órdenes de Tamburini de hacerlo volver a Europa. Schabel llegaba a la ciudad de Ámsterdam en 1714. Poco después recibía de nuevo la autorización de volver a Curazao. Sin embargo, Tamburini cambiaría de parecer al enterarse de la existencia de una mujer en la vida del misionero. Se le ordenó despedirla inmediatamente de su casa, pero la renuencia de Schabel obligó al general a expulsarlo de la orden. Esto ocurría el 22 de diciembre de 1714. Prueba de su vida marital es el registro en los archivos parroquiales de Curazao, para el año de 1727, de dos mujeres de nombre Schabel: Catharina Isabella Schabel, viuda del ciudadano bohemio Jan Schirowsky, y una menor llamada Isabella Schabel, encargada al cuidado de la viuda de Jan Thielen por petición del jesuita Bruno Pauwels (Schunck 107).

En la misiva de 1715, donde Tamburini anunciaba al provincial del Nuevo Reino el despido del jesuita checo, se recomendaba, asimismo, prohibir a todos los jesuitas de Casanare el uso de indias para el servicio y el aseo de la casa misionera, y se encargaba a los superiores un castigo ejemplar para todo aquel que no cumpliera estrictamente esta orden ${ }^{11}$ (ARSI, EP 52 f. 241). Podemos preguntarnos si esta decisión tiene que ver directamente con el paso de Schabel por la misión de

11 De Tamburini a Mateo Mimbela del 16-03-1715. La misma orden fue reiterada en 05-051719. 
Casanare hacia 1697. Si tal es el caso, podríamos interpretar todas las desobediencias del misionero como indicios de una trasgresión de la regla de castidad que lo habría llevado progresivamente a abandonar su vocación religiosa.

El caso de Schabel no es único. De acuerdo con el historiador jesuita Antonio Astrain, durante el siglo XVII los casos de "vida deshonesta" fueron moneda corriente en España y América. Por ejemplo, el padre Luis de Valdivia, misionero en Chile, fue acusado en los años 1620 de tener relaciones carnales con las indias araucanas. En España Astrain contabiliza, entre 1615 y 1652, más de 30 casos de jesuitas que, habiendo huido del colegio por una violación de la regla de castidad, fueron expulsados de la orden después de haber sido encerrados en calabozo por varios meses, a fuer de castigo ejemplar (Astrain 701).

El padre Juan Rivero, autor del Teatro del desengaño, debió de haber conocido las mismas dificultades de Schabel como misionero en Casanare. Encontrarse en un pueblo de salvajes lleno de indias semidesnudas y lejos de la corrección del superior debió de ser, ciertamente, una ruda prueba para la castidad. En su obra Rivero anota, por medio del personaje del escarmiento, los casos más ejemplares y espantosos de "atentados contra la pureza", sacados de teólogos y moralistas jesuitas. Así, el caso contado por el padre Alonso de Andrade sobre un mal sacerdote que durante la misa aparecía desnudo frente a los fieles, seguido "de un demonio tan feo y tan horrible, que parece había recopilado en su atezado rostro toda su fealdad el infierno", o el caso narrado por el padre Eusebio Nieremberg, de un "mancebo tan desenfrenado" que vio una noche salir de una tumba "una espantosa llama de infernal fuego" y la voz de ultratumba de un sacerdote libertino, muerto hacía poco, que le aconsejaba dejar su escandalosa vida, si no quería terminar como él en el infierno. Más escabrosa es la historia del padre Manuel de Texeira, quien asegura que un clérigo murió en el acto carnal por haberle prometido en vano a Dios la enmienda de sus pecados. La historia evocada por el padre Ortigas es también sobre el escarmiento: un viejo clérigo que vivía amancebado se encontró agonizante en su lecho de muerte sin poderse encomendar a Dios, cuando, de pronto, "bajaron del techo muchas arañas diferentes, mayores que sapos, las cuales le rodearon la cabeza y la almohada". El enfermo "arrancó de su pecho un gemido espantoso diciendo con voz tremenda: condenado estoy y se le arrancó el alma, que llevaron aquellos demonios sin duda a los infiernos" (Rivero 72-78).

\section{Conflictos en la frontera misionera}

El caso de Alejo Schabel ilustra igualmente el problema de la frontera política y misionera entre el continente español y las colonias holandesas y francesas de las Antillas y la Guyana. La misión de Schabel en Curazao, cerca de la costa 
venezolana (a la que aún en el siglo XVIII se le suele llamar Tierra Firme), se encontraba en medio de dos mundos contradictorios, pero interrelacionados: los católicos del continente, entre los cuales los más influyentes eran terratenientes, encomenderos y hacendados productores de tabaco y cacao, y misioneros capuchinos y franciscanos que reducían a los indios de la región de los llanos de Barinas, Cumaná, Barcelona y Caracas para compelerlos a participar en este sistema económico; $y$, por otra parte, el mundo de los mercaderes y comerciantes de las Antillas, generalmente de portugueses cripto-judíos y de holandeses de confesión judía o protestante, que se enriquecieron, como hemos visto, con el contrabando de manufacturas europeas y el comercio de esclavos negros. Dentro de este contexto, es preciso situar el rol de los franceses. Aunque muchos de los colonos pobladores de origen francés eran protestantes, con el tiempo las Antillas se fueron volviendo católicas gracias a la presencia misionera francesa. Este es el caso de la isla de Curazao, donde existía una comunidad de comerciantes católicos de origen francés. Las rivalidades entre estos y los holandeses están ligadas, entre otros factores, a la coyuntura de la Guerra de Sucesión, pues Francia y España eran por entonces aliados contra Holanda. Lo que estaba en juego era, entre otras cosas, el control de ciertos mercados hacia el continente, como en el caso del asiento de esclavos, que comienza, justamente por los años de la guerra, al pasar de manos de la sociedad holandesa de Baltasar Coyman a la de los franceses.

Estas rivalidades repercuten en la política misional americana. Cuando Schabel regresó a la isla en 1705, huyendo de la hostilidad que sufrió en el continente, fue recibido calurosamente por la comunidad católica holandesa. Por el contrario, los franceses y su pastor, el padre Víctor de Dôle, fueron desde el principio muy hostiles al jesuita. Dôle era un religioso capuchino de origen francés que había dejado su país "porque había, escribe Schabel, predicado contra el sínodo de París, como él mismo me lo contó" (ARSI, NRQ 16-1 f. 52). Pasó luego a la isla de Martinica, donde tuvo, igualmente, problemas con su superior hacia 1694 (ARSI, NRQ 16-1 f. 52; APF, 83 f. 103; cfr. Schunck; David 221). El religioso se refugió luego en el continente venezolano, en la misión de capuchinos aragoneses de Cumaná. Pero allí también hubo problemas. Dôle viajo entonces a Roma, donde consiguió patentes de la Congregación de Propaganda Fides, patentes según las cuales - escribe Schabel — "pero quién podría creerlo [...] se le eximía por el resto de sus días de la regla de obediencia para con su orden y sus superiores" (ARSI, NRQ 16-1 f. 52).

Los conflictos entre Víctor de Dôle y Alejo Schabel en 1705, y otros posteriores entre el jesuita y un religioso agustino, amigo del capuchino francés, parecen tener como telón de fondo las rivalidades político-pastorales entre la Compañía de Jesús y el Dicasterio Romano para la Propagación de la Fe, también llamado Congregación de Propaganda Fides. Fundado en 1624, este órgano de la Santa Sede fue creado para dirigir en todo el mundo la política misionera, en una época 
en que las órdenes religiosas, y particularmente la Compañía de Jesús, tenían la hegemonía misionera.

La congregación abría la acción misionera al clero europeo, particularmente a las nuevas órdenes romanas y al clero secular, excluido hasta mediados del siglo XVII de las misiones lejanas. Para el caso de América, estas fueron durante largo tiempo monopolio absoluto del patronato español y portugués, y, por ende, de los jesuitas, quienes, al estar más cerca del poder real en Lisboa y en Madrid, cumplían un papel preponderante en materia misional. Esta doble jurisdicción misionera, es decir, por un lado Roma y por el otro el Rey, fue muy problemática en el caso de las Antillas y de la costa norte del continente suramericano llamada Tierra Firme, a causa de la influencia francesa en esta parte del Nuevo Mundo. Dentro de este contexto, es natural que hayan surgido enfrentamientos entre los jesuitas, fieles al patronato, y los capuchinos franceses y aragoneses, más influenciados por las políticas misioneras de la Congregación.

En 1645, bajo la influencia del cardenal Richelieu y del secretario de la Congregación, Francesco Ingoli - y a pesar de las instancias del Cardenal español Albornoz-, el Papa autorizaba una misión de dominicos franceses en la isla de Guadalupe (Pizzorusso 584). Nuevas tentativas misioneras fueron lanzadas por Francia a partir de este punto, en 1646. Un contingente de capuchinos franceses se instaló entonces en la isla de Saint Christophe. Cuando varios de estos capuchinos pasaron al continente, a la región de Guarapiche, cerca de Paria, los jesuitas protestaron e instalaron una misión en la región de Santo Tomás de Guayana, para contrarrestar la influencia capuchina. Estas rivalidades son todavía perceptibles durante el siglo XVIII.

En 1729 un clérigo francés llamado Nicolás Gervais de Labrid, que se instalaba en Tierra Firme con el título de obispo del Orinoco, promulgado por la Congregación, fue cruelmente asesinado por los indios, sin la menor represalia por parte de las autoridades españolas (Useche 95). En las misiones del Orinoco, a pesar de los esfuerzos del padre jesuita José Gumilla por repartir el campo apostólico del bajo Orinoco con los capuchinos catalanes, las relaciones entre las dos órdenes fueron siempre tensas, a causa de la frontera misional de Cabruta, centro importante de comercio en la región.

Pero volvamos a los acontecimientos de 1705. Según nuestro jesuita, el capuchino Víctor de Dôle había ya vivido en Curazao en tiempos del gobernador Jacob Becks, y había vuelto a la isla gracias a la ayuda de un poderoso comerciante judío llamado Felipe Henríquez (ARSI, NRQ 16-1 f. 53). En el relato de 1705 Schabel cuenta en detalle el origen de su rivalidad con el capuchino: 
Esta frecuente y santa costumbre de decir la misa todos los días, propia a los religiosos de nuestra Compañía, ha parecido particularmente inoportuna a este capuchino. Los celos lo han invadido, pues gentes de todas las naciones (portugueses, españoles, alemanes y belgas) han venido a verme para confesar sus pecados, dejándolo de lado. Casi todos los alemanes y los belgas criollos, es decir los concebidos y criados en esta isla, no se habían confesado desde hacía cinco años por falta de un sacerdote que hablara su lengua. Algunos no lo habían hecho desde hacía diez o veinte años y otros no se habían confesado jamás. El afecto y concurso de los católicos para conmigo me hizo odioso a los ojos de aquel. Esta es la razón por la cual a comenzado a perseguirme. (ARSI, NRQ 16-1 f. 55)

Al parecer, Dôle se había apoderado "...del único ornamento sagrado destinado al sacrifico de la misa", entre otros objetos de culto que el jesuita había dejado en la isla guardados en una caja sellada, en su primer paso por Curazao hacia Holanda. Viéndose obligado a pedirle prestados los objetos que le habían pertenecido, Schabel parece armado de paciencia. Sin embargo, el capuchino, al igual que lo había sido Schabel en el continente, fue acusado ante el Consejo de Indias de espionaje. De acuerdo con las cartas enviadas al rey por el gobernador de Venezuela en 1706, Víctor de Dôle pertenecía a una red de espionaje del partido pro austriaco, que pretendía organizar una conspiración ${ }^{12}$ bajo el mando de un cierto Bartolomé Capocelato, conde de Antería, y del judío Felipe Henríquez, ambos instalados en Curazao y amigos del padre capuchino (Borges, Los aliados 38; La Casa 129-132). ¿Tuvo algo que ver el jesuita con estas denuncias hechas al Consejo de Indias?

El 11 de abril de 1705 Schabel se deshacía por fin del capuchino, quien viajaba a Viena con el susodicho Conde de Antería. Aunque Víctor de Dôle fue declarado personna non grata por las autoridades de la isla, su influencia era todavía temida por el jesuita. Dos años más tarde Schabel obtuvo informaciones sobre el capuchino escudriñando cuidadosamente en el correo. Según la carta de una "cierta señora" que había tenido entre las manos, Dôle se mostraba urgido por averiguar la razón de su expulsión de la isla. Al parecer, residía en algún lugar de la costa venezolana y se sospechaba una confabulación contra su persona, tal como lo escribe en su diario el 3 de noviembre de $1707^{13}$ (ARSI, NRQ 16-1

12 El rumor de conspiración contra el rey borbón, debe ser relacionada con otros rumores del mismo estilo. Así, por ejemplo, hacia 1635 las autoridades españolas temían un complot organizado por los judíos portugueses de Cartagena y Lima con el fin de que los holandeses se anexaran el reino del Perú (Navarrete 11).

13 Texto original: "Post haec audio notitias, quod exul capucinus litteras ad certam mulierem huc scripserit a litore Caracense. Significat, quod ad urbem Caracensem tendat, ubi et unde 
f. 11). El capuchino llevaba una campaña en Venezuela para desacreditar al jesuita divulgando su supuesta excomunión, y lo culpaba de su exilio de Curazao. Pese a ello, Schabel ganaba cada día más adeptos, entre los cuales se encontraban los antiguos amigos del capuchino.

Otro religioso vendría, sin embargo, a oponerse al trabajo pastoral de nuestro jesuita. Se trata del padre Agustín Caicedo y Velasco, un religioso agustino que había sido en parte responsable de las calumnias proferidas contra Schabel cuando este viajaba a Caracas en 1704. De acuerdo con los documentos revisados en el Consejo de Indias, Caicedo, quien se encontraba en 1704 en el continente, correspondía con el padre capuchino Víctor de Dôle, y con otros personajes próximos del partido austriaco. Al igual que Dôle, Caicedo había obtenido una patente de la Congregación de Propaganda gracias a la influencia de dos importantes amigos suyos en el seno de esta institución: el marqués de Cavanillas y el conde de la Corzana $^{14}$. De acuerdo con los informes del Consejo (AGI, SF 262 f. 22), Caicedo había viajado desde Puerto Príncipe hasta Roma hacia 1709, con el fin de confirmar sus derechos de misionero ante el general de su orden. Había pasado luego a Nápoles, Barcelona y Rótterdam. Desde esta última ciudad el religioso se había embarcado hacia Curazao, donde llegaba en 1712 con patentes de misionero. En 1713 Schabel escribía una carta contra él al obispo de Caracas, y otra al jesuita Guillermo Daubenton, entonces confesor del Rey de España. En esta misiva Schabel acusaba a Caicedo de ser un espía del archiduque de Austria y de haber propagado ciertos pasquines contra el Rey de España y contra la fe católica ${ }^{15}$ :

... había recogido siete libros infames y perniciosos que había esparcido el Padre Caicedo de Autores Jansenísticos, y contra Religión de la Compañía, dedicados al conde de la Corzana, y que haría las mas exactas diligencias para recoger otros, respecto de tener entendido que hasta el numero de cua-

causam sui exilii scire cupid, ut scribit. Hinc infero : ergo causam sui exilij nescivit; qua igitur conscientia hic catholicis dicere et asseverare potuit, quod ego ejus exilij causa fuerim. Parco ei, quantum possum, calumniam, sed non quantum indiget" (traducción libre del autor).

14 Diego Hurtado de Mendoza y Sandoval, tercer conde de la Corzana, fue uno de los aliados del partido austriaco durante la guerra de sucesión. En 1697 fue nombrado maestre de Campo del ejército de Cataluña por Carlos II. Allí combatió por primera vez a los franceses al lado del príncipe de Darmstad. A la muerte de Carlos II, tomó partido por los Austrias. En 1706 fue nombrado por el archiduque virrey de Cataluña, cargo que desempeñó hasta la derrota de Barcelona. En 1709 era ministro del gobierno disidente del archiduque (Lafuente IX 141).

15 Caicedo había escrito, en efecto, un libelo contra los jesuitas, publicado en Villafranca (Navarra) en 1712. El opúsculo estaba dedicado al conde de la Corzana, y llevaba como título: "Expugnatio appelationis vel appellantis a decreto et executione Apostolici, cum potestate Legati a Letere in Regno Chinarum, D. Caroli de Tournon, emanati die 25 Ianuarii 1707”. Caicedo atacaba en particular un texto del agustino Álvaro de Benavente, obispo y vicario apostólico de Kiangsi, en el cual el prelado tomaba la defensa de los jesuitas en la famoso caso de los ritos chinos (Rivas Saconni 187-190). 
trocientos había de esparcir y que se hallaba con noticia de haberse expedido ordenes generales para prender al Padre Caicedo. (AGI, SF 262; cfr. Rey Fajardo 281)

Caicedo se defendía ante el obispo en una carta enviada desde Curazao el 27 de enero de 1714:

Siendo yo español no puedo menos que defender el derecho que mi nación tiene en la propagación de la Fe en esta Isla, y Predicación en ella. Pues desde el año de 1525 había sido el clero y los regulares de nación española los que han trabajado en esta viña, sin que ningún Padre flamenco, ni alemán jesuita, ni jesuita español aya tenido la menor parte en la predicación, sino desde que el P. Miguel Alejo Schabel se introdujo motu propio a ello. (AGI, SD 794; cfr. Borges, Los aliados 36)

Caicedo confirmaba al obispo que era “...católico español, no católico flamenco, ni francés, ni alemán, pues cuanto obr[aba] [era] sin interés del menor ochavo y cuanto [hacía era] de [su] propia bolsa" (AGI, SD 794). De acuerdo con esta carta, Schabel había destruido todas las buenas obras pastorales hechas anteriormente por su amigo Víctor de Dôle, de tal suerte que se veía obligado a buscar nuevos fieles entre la gente más humilde de la isla. Caicedo parece determinado a deshacerse de Schabel cuando escribe:

El señor marqués de Bay y mis parientes entre ellos el conde de las Torres que es vicario general de España mirarán por mí [...] Mi persona y parentela se hallan francamente injuriados [...] y por lo que mira a cierto sujeto que escribió de aquí al Sr. Obispo que io era jansenista, le he cogido cartas que parecerán en Roma. (AGI, SD 794).

Es muy posible que el correo de Schabel, interceptado por Caicedo en 1713 y enviado luego a Roma en 1714, haya sido la causa de su despido de la Compañía de Jesús. Recordemos que Tamburini había sido informado en abril de 1714 de la existencia de una mujer en la vida del jesuita.

En 1715 la Congregación de Propaganda Fides, que no estaba al corriente de la misión de Schabel, nombraba oficialmente a Caicedo como prefecto apostólico y representante de la Santa Sede para las islas holandesas del Caribe (APF, $85 \mathrm{f}$. 440v; cfr. Schunck 107). Sin embargo, y gracias a Schabel, los jesuitas se mantuvieron en la isla, considerada oficialmente territorio de misión por la provincia de Flandes. En 1715 el jesuita belga Pierre Picquerie tomaba su lugar. Durante los años 1720 la cohabitación entre Picquerie y Caicedo fue difícil. 
En 1728 el arzobispo nombrado para Santa Fe, Antonio Álvarez de Quiñones, en su viaje hacia la Nueva Granada acompañado de un confesor jesuita, hacía escala en la isla de Curazao para hacer una visita a Caicedo. El prelado había sido encargado por el Consejo de Indias para convencer al religioso de regresar a Santa Fe. "Sin duda, escribe Álvarez de Quiñones al rey, lo hubiera conseguido, si no fuera en él tan poderoso el miedo y temor reverencial que me manifestó le asiste de la justa indignación de V.M. por la dedicatoria que hizo de un libro al conde de la Corzana, en el tiempo que este se hallaba auxiliando las armas de las potencias enemigas" (AGI, SF 397 f. 152). Todavía en 1736 los jesuitas temían la presencia de Caicedo en Curazao. El provincial de la Nueva Granada, el padre Jaime López, que había viajado a la isla para visitar al padre Vannschelle, entonces su misionero, informaba al general Francisco Retz sobre las dificultades que la compañía había tenido con el agustino. El propio provincial había sido acusado, en una carta anónima enviada al Consejo desde Curazao, de haber llevado de la isla una gruesa cantidad de mercancía (AGI, SF f. 400; cfr. Pacheco 254). A pesar de las dificultades encontradas, los jesuitas permanecieron en Curazao hasta 1742 (Schunck 109).

$$
* * *
$$

A partir del análisis de la conducta de Alejo Schabel plantearemos, a manera de conclusión, dos preguntas que resultan, a nuestro modo de ver, interesantes.

1. ¿Por qué, conociendo el expediente de desacato de Schabel (huida del Nuevo Reino, regreso a América sin autorización, proyectos comerciales en Rótterdam y en Praga, acusación de espionaje, comercio apóstata en Curazao), las instancias superiores jesuitas parecen tolerar su actitud?

En el caso de la observancia religiosa a la obediencia la respuesta parece delicada; sobre todo, si tenemos en cuenta que la obediencia ha sido identificada a menudo como uno de los rasgos más sobresalientes de la organización jesuita. En efecto, la base de la organización es la estricta sujeción al superior, como en las órdenes militares de la edad media.

La regla de obediencia recubre, asimismo, un fundamento ascético-espiritual. Obedecer es el mejor medio para deshacerse de la propia voluntad y permanecer en un estado de "indiferencia", donde el ideal es contentarse con lo que se manda, entregarse a la voluntad ajena. Por eso, cada individuo jesuita debe estar dispuesto a reconocer en su superior la autoridad de Dios. De ahí el lema jesuita perinde ac cadaver. "Nos hemos de dejar llevar y regir y gobernar de nuestros Superiores y de la providencia divina y paternal que Dios ejercita por medio de ellos — escribe el célebre jesuita Gonzáles Dávila — como un cuerpo muerto [...] que, así como el cuerpo muerto no tiene movimiento de sí, sino el que le dan, así el religioso, movido de su Superior se mueve" (Gil González 159). 
¿Por qué, entonces, la actitud de Schabel no es condenada por los superiores durante su desempeño en Europa y en Curazao? La respuesta, a mi modo de ver, tiene que ver con el hecho de que esta actitud de sumisión se extiende, sobre todo, a la base de la organización, pero se aplica de manera diferente cuando se trata de la élite jesuita, a la cual se accede a partir del cuarto voto; es decir, cuando el candidato es investido profeso. En el caso de Schabel, sus actuaciones personales pueden oscilar entre la desobediencia y la iniciativa individual, si tomamos en cuenta que el jesuita es un profeso y que su acción misionera en Curazao es, en cierta medida, una misión pionera: establecer por primera vez una permanencia católica en territorio calvinista. De esta suerte, en la medida en que sus actuaciones sirven a la causa de la organización, son vistas como iniciativas inspiradas por Dios, de acuerdo con los ejercicios espirituales, que deben guiar toda decisión jesuita. Esta actitud ambigua u oscilante no es tan rara en los miembros de la élite jesuita. Recordemos el famoso caso del padre Alonso Sánchez desobedeciendo al general Acquaviva y tomando partido en su contra en la famosa controversia por la conquista de la China, a finales del siglo XVI (Martínez 15).

Recordemos, igualmente, el caso del padre Lucas Rangel, brillante criollo de Santa Fe varias veces censurado por su "conducta aseglerada" y acusado de desobedecer a sus superiores, y quien partió a España en 1637, en compañía del marqués de Sófraga. Al parecer, Rangel viajaba para negociar su nominación en el tribunal de la Inquisición de Cartagena (Pacheco, 1959 f. 565; AHN, INQ f. 1304-5).

Se puede, entonces, decir que en la alta jerarquía de la orden la obediencia no era tan importante como la iniciativa individual, que jugaba un rol primordial en el desarrollo de la expansión ideológica y territorial de la orden.

2. ¿Cuál fue exactamente el rol jugado por Schabel en Europa y en América en los asuntos de comercio? ¿Fueron estos parte de su misión?

Como ya hemos insinuado más arriba, aunque el jesuita parece haber participado en varias negociaciones de tipo mercantil, estas parecen haber sido ventiladas por los superiores jesuitas de los Países Bajos y de Roma. Aunque las actividades de comercio eran estrictamente prohibidas por la Santa Sede para todo el clero, era frecuente que asuntos de crédito o de comercio fueran tratados por religiosos, en la medida en que el beneficio no fuera directamente relacionado con su actuación; es decir, sin enriquecimiento directo del individuo, acto totalmente contrario a la observancia religiosa. Tratándose del cuerpo social, la cuestión era diferente, puesto que la acumulación de riquezas era, en ese caso, no solo permitida, sino necesaria para el poder pastoral.

De esta manera es posible pensar que el desempeño de Schabel no haya tenido más que una retribución o limosna de parte de sus amigos o prosélitos, y que el 
enriquecimiento se haya puesto al servicio de la misión, puesto que no hay ninguna prueba de enriquecimiento personal, salvo la posterior a su despido de la compañía. En el caso de la misión de Curazao iniciada por Schabel, como en el de otras misiones americanas de la compañía, es difícil diferenciar las actividades que se hacen "por la mayor gloria de Dios y el servicio de las almas" de las que sirven directa o indirectamente a intereses privados, puesto que ambos mundos, el de la caridad y de las obras pías y el de las élites económicas, están estrechamente relacionados.

A nuestro modo de ver, el rol de Schabel como informante en esta materia es más evidente. Recordemos, además, que el jesuita no es el único en ser acusado de espía o informante. Los padres Dôle y Caicedo tienen, a mi modo de ver, muchos puntos en común con el jesuita. Los tres religiosos son acusados de apostasía y de espionaje, los tres aparecen implicados en asuntos de comercio ${ }^{16}$, los tres viajan a Europa y tienen problemas con la obediencia y la autoridad de sus respectivas órdenes. Además, en el contexto de rivalidad misionera entre el patronato y la Congregación de Propaganda Fides, los tres misioneros parecen enfrentarse para obtener el poder pastoral católico en Curazao, una lucha ensañada en la cual la actividad de información parece haber sido primordial.

Prueba de ello son los correos enviados a Europa a la aristocracia mercante de origen católico y los informes y diarios escritos para ser enviados a Roma al general Tamburini, y en los cuales se informa concretamente sobre el movimiento de los barcos franceses y sobre el estado del comercio de la isla. Esta labor informativa es patente también en las cartas enviadas al jesuita confesor Guillermo Daubenton. Es, pues, muy probable que el jesuita checo haya sido utilizado por la Compañía como informante en un momento crucial de cambio de la política europea. Por eso no creemos que sea una coincidencia que el desempeño misionero de Schabel coincida perfectamente con la cronología de la guerra de Sucesión (1701-1714).

16 De acuerdo con una carta de Schabel a Guillermo Daubenton, el padre Caicedo y Velasco estaba en contacto con Pedro Marauet, un comerciante de la costa venezolana (AGI, SF f. 262; cfr. Rey Fajardo 281). El historiador C. Goslinga cuenta también que Caicedo estuvo directamente implicado desde Curazao en el comercio de tabaco (Goslinga 259). Para mayor información sobre este religioso, véase el artículo de Van Luijk O.S.A. 


\section{Bibliografía}

\section{Fuentes primarias}

Archivo Romano Societatis Jesu, Roma, Italia (ARSI)

Novo Regno et Quito (NRQ)16-I.

Notitia Admodum Reverendo Patri Tamburini Praeposito Vicario generali

Soceitatis Iesu, a Patre Michael Alexio Schabel eiusdem Societatis missionnario, data anno 1705 nto. 9 aprilis ex America, De nova illic missione in Insulis Curacacao, Bonaire, Aruba, atque ad fumen Apure, in Indica terra firma Novi Regni Granatensis.

Diurnum a Michael Alexio Schabel (21/10/1707-04/02/1708)

Fondo Gesuitico (FG) 756.

Bohemia (BOH) 21, 22, 24, 26.

Flandes-Bélgica (FB) 8.

Epistolae Generalis (EG) 52.

Archivo General de Indias, Sevilla, España (AGI)

Audiencia de Santa Fe (SF) 250, 262, 397,400.

Audiencia de Santo Domingo (SD) 794.

Archivo Provincial de Toledo, Alcalá de Henares, España (APT)

Archivo Histórico Nacional, Madrid, España (AHN)

Inquisición (INQ) 1304.

Archivo Provincial de Flandes, Bruselas, Bélgica (APF).

\section{Fuentes secundarias}

Astrain, Antonio S.I. Historia de la Compañía de Jesús en la Asistencia de España. 7 vols. Madrid: Sucesores de Rivadeneyra, 1902-1925. 
Blet, Pierre S.I. "Les fondements de l'obéissance ignatienne". Archivum Historicum Societatis Iesu 25 (1995): 514-538.

Borges Jacinto del Castillo, Ana Lola. La Casa de Austria en Venezuela durante la guerra de sucesión española. Tenerife: Goya,1963.

--- "Los aliados del archiduque Carlos en la América Virreinal". Anuario de Estudios Americanos 27. (1970): 321-370.

--- "Las actividades políticas de un misionero checo en Europa y América (16991713)" Ibero-Americana Pragensia 8 (1974): 188-194.

Certeau, Michel de S.I. "L'universalisme ingatien : mystique et mission". Christus 50 (1966): 173-183.

--- "L'espace du désir ou le fondement des Exercices Spirituels". Christus 77 (1973): 118-128.

David, Bernard. Dictionnaire biographique de la Martinique: "Le clergé" (1635-1845). T I. Fort de France: Société d'histoire de la Martinique, 1984.

González Davila, Gil S.I. Pláticas del Padre Gil González Dávila sobre las reglas de la Compañía de Jesús. Barcelona: Juan Flores, 1964.

Lafuente, Modesto. Historia General de España. Madrid: Francisco de P. Mellado, 1862.

Maria N., "Relación histórica que de su viaje a Cocorote, Barquisimeto, Araure, Guanare, Tucupio, Barinas y el Real hace el misionero Jesuita Miguel Alejo Schabel en el año de 1704". Boletín del Centro Histórico Larense 6.9 (1943-1944).

Martínez Millán, José. "La crisis del «partido castellano» y la transformación de la Monarquía Hispana en el cambio de reinado de Felipe II a Felipe III" Cuadernos de Historia Moderna, Anejos. 2 (2003): 11-38.

Navarrete, Maria Cristina. "Judeo-conversos en la audiencia del Nuevo Reino de Granada, siglos XVI y XVII”. Historia Crítica 23 (2003): 73-90.

Oostindie, Gert y Paasman, Bert. "Dutch Attitudes Towards Colonial Empires, Indigenous Cultures, and Slaves". Eighteenth-Century Studies 31.3 (1998): 349-355.

Pacheco, Juan Manuel S.I. Los jesuitas en Colombia. T 1-3. Bogotá: San Juan Eudes, 1959-1989. 
Pizzorusso G. "Propaganda fide e le missioni cattoliche sulla frontiera politica, etnica e religiosa delle Antille nel XVII secolo". Mélange de l'Ecole française de Rome 109. 2 (1997): 581-599.

Polišenský, Josef. "Un poco de polémica sobre las actividades de Miguel Sabel". Ibero-Americana Pragensia 8 (1974): 194-197.

---. y Veber, Lubomír. "Miguel Sabel y orígenes del comercio americano con el vidrio de Bohemia". Ibero-Americana Pragensia 5 (1971): 93-115.

Rey Fajardo, José (del). S.I. Bio bibliografía de los jesuitas en la Venezuela Colonial. Carácas: Universidad Católica Andrés Bello, 1974.

---. "Miguel Alejo Schabel S.J., Escritor, aventurero y misionero". Boletín Universitario de letras 1 (1993): 169-195.

---. Biblioteca de escritores jesuitas neogranadinos. Bogotá: Universidad Javeriana, 2006.

---. "El P. Agustín Beltrán Caicedo y Velasco, prefecto apostólico de Curazao (1715-1738)" Missionalia Hispanica 17. 49 (1960): 119-134.

Rivas Sacconi, José Manuel. El latín en Colombia, bosquejo histórico del humanismo colombino. Bogotá: Instituto Caro y Cuervo, 1949.

Rivero, Juan S.I. [1742] Teatro de el desengaño. Bogotá: Biblioteca de la Presidencia de Colombia, 1956.

Schunck, Cristine. "Michel Alexius Schabel S.J. Notitia de Coraçao, Bonayre, Oruba (1705) and Diurnum (1707-1708)". Archivum Historicum Societatis Jesu 13 (1997): 89-162.

Stepanek P. “El Jesuita Miguel Schabel (Sabel), misionero en Venezuela, y la iconografía del cristal de Bohemia. Montalbán 25 (1993): 75-98.

Useche Losada, Mariano. El proceso colonial en el alto Orinoco-Río Negro (siglos XVI-XVIII). Bogotá: Banco de la República, 1987.

Fecha de recepción: 9 de abril de 2008

Fecha de aprobación: 25 de septiembre de 2008 